\title{
The aspects of reproduction of Clathrus archeri (Berk.) Dring by re-situ method in the National Nature Park Hutsulshchyna
}

\author{
Mariia Pasaylyuk $^{1}$, Yurii Petrichuk ${ }^{2}$, Nadiia Tsvyd ${ }^{3 *}$, Maryna Sukhomlyn ${ }^{4}$ \\ ${ }^{1}$ National Nature Park Hutsulshchyna, 84 Druzhba Street, Kosiv, Ivano-Frankivsk Region 78600 , Ukraine; ${ }^{2}$ National Nature Park Hutsulshchyna, \\ 84 Druzhba Street, Kosiv, Ivano-Frankivsk Region 78600, Ukraine; ${ }^{3}$ Department of Plant biology, Educational and Scientific Centre “Institute \\ of Biology and Medicine" of Taras Shevchenko National University of Kyiv, 2 Hlushkova Avenue, Kyiv 03127, Ukraine; ${ }^{4}$ Department of Plant \\ Biology, Educational and Scientific Centre "Institute of Biology and Medicine" of Taras Shevchenko National University of Kyiv, 2 Hlushkova \\ Avenue, Kyiv 03127, Ukraine
}

*Tel: +380 994951183, e-mail: ayidants23@gmail.com

\begin{abstract}
The biodiversity preservation is one of the main missions on present days. Two main trends of biodiversity conservation in-situ and ex-situ are known today. However, use of both these methods is not enough for the protection of rare species of macromycetes. Therefore, we need a new method for protecting the rare species of fungi, which support their vital process in not only the laboratory but also reproducing it in nature.

In this article, we propose the use of a new method of preserving the rare species of fungi in nature. The re-situ is a method that provides introducing and support of vital functions of mushroom in nature with the forming of their basidioma.

For our research, we used Clathrus archeri (Berk.) Dring, which is included in the Red Data Book of Ukraine.

It was found that the substrate on which the mycelium was grown and subsequently used for natural conditions had a significant influence on the success of 'reinoculation' of $C$. archeri. Among all the investigated substrates, only one (beech shavings) proved to be suitable for growing of sowing mycelium of $C$. archeri. The research showed that the reproduction of $C$. archeri in nature should be held on non-forest experimental sites, mainly on meadows during the spring months.
\end{abstract}

Keywords: Fungal conservation, Phallaceae, reinoculation, basidioma, pure culture.

\section{Introduction}

Nowadays many fungal conservation groups such as the European Council for the Conservation of Fungi, the International Union for Conservation of Nature (IUCN), the Fungal Committee and the International Society for Fungal Conservation are being created. This fact is demonstrating the growing interest in the preservation of fungi (Allen \& Lendemer 2015). The program of the European Mushroom Preservation Community provides a number of measures, among which is the formation of lists of species that are under the danger of extinction. The detection of new places of growth of the mushroom species, included in the Red Data Book on the unexplored and less explored territories, is also important (Birsan et al. 2014). Great attention should also be paid to the annual observations of the already detected and traced localities of rare mushroom species. This data serves as the basis for the creation of mycological reservation contributing to the protection of a mushroom biodiversity.
Thus, the systematic monitoring of the already detected localities of mushroom species included in the Red Data Book of Ukraine is being held in the Carpathian Mountains (National Nature Park Hutsulshchyna), as well as the work on finding new places of growth of rare species of macromycetes (Petrichuk, Pasaylyuk 2015). There are several localities of rare species of mushrooms (Hericium coralloides (Scop.) Pers., Hericium alpestre Pers., Sparassis crispa (Wulfen) Fr, Polyporus umbellatus (Pers.) Fr. and so on) on the territory of the National Nature Park Hutsulshchyna, presence of which became the basis for creation of the natural reserve 'Kamenistyi khrebet' with an area of 30 ha. Such kinds of means are absolutely explained not only from the viewpoint of ecological safety or nature-preserving grounds but of saving the everyday life and customs of the local people as well.

Two main trends of biodiversity conservation in-situ and ex-situ are known today (Hawksworth, 1991). The first in-situ method is based on a population-species and ecosystem level. Its main task is preserving certain species and biocenoses of their localities. However, the conservation measures of this

Wpłynęło: 24.06.2015 r., zrecenzowano: 17.10 .2015 r., zaakceptowano: 4.11 .2015 r. 
method do not always guarantee complete preservation of the fungi that are growing in this area. Therefore, the ex-situ method is one of the perspective approaches for the preservation of rare and endangered fungi. Its main task is to preserve the gene pool of macromycetes in pure culture in specialized collections (Venturella 2004).

However, for the protection of rare species of macromycetes, it is not enough only to protect their habitats by the method of ex-situ or to preserve their genome by the method of in-situ (Hawksworth 1991). Even the combination of these two methods cannot always guarantee the preservation of the species, in addition to increase of the amount of their localities in nature. Therefore, we need new method for the protection of rare species of fungi that support their vital process not only in the laboratory, but also to reproduce it in nature.

We have developed and tested views on the preservation of mushroom biodiversity, which combine the efforts of mycologists-inventories and those who deal with the question of investigating the cultural peculiarities of different mushroom strains in laboratories. Re-situ is a method that provides introducing and support of vital functions of mushroom in nature by forming their basidioma (Petrychuk et al. 2014). We suggest that such kinds of investigations can become new tools of nature-protecting actions.

In our research, we chose a rare species of fungus to Ukraine's Clathrus archeri (Berk.) Dring, also known as 'devil's fingers'. The C. archeri is native to Australia and New Zealand. However, it is also present on the territory of Europe, where it was found first in 1914 in France. Although in recent years, it is intensively distributing on the territory of Europe (in particular Ukraine and Poland), it is listed in the Red List of the Netherlands and the Red Data Book of Ukraine (Zykova 2007; Didukh 2009; Szczepkowski, Obidziński 2012).

C. archeri is a species with a disjunctive distribution area, belonging to the macromycetes-ephemers, a disappearing category (Didukh 2009). It grows in broad leaved and mixed forests with Beeches, Hornbeams, Oaks, Ashes, Pines, some species of Maples, Willows and so on (Malaniuk 2013). According to the ecological-trophic affiliation, C. archeri is referred to as subsoil saprotrophs and is a soil-forming mushroom. Nowadays, there is no information about the propagation and cultivation of this species in specially created experimental conditions.
The aim of our work was getting the indigenous strains of C. archeri in pure culture form and its subsequent recultivation, taking into account its trophic affiliation and information about the natural place of growth.

\section{Materials and methods}

The work on the reproduction of $C$. archeri consisted of several stages. The first stage of work comprised of putting the indigenous $C$. archeri strains into a pure culture. Mycological material was collected on the territory of the National Nature Park Hutsulshchyna. The culture was segregated while in 'an egg' stage, when the basidioma was still covered with a layer of mucilage and wrapped in a thick peridium. The inoculum of basidioma was placed into a Petri dish with potato dextrose agar medium, and was put into an incubator at the temperature of $22-24^{\circ} \mathrm{C}$ (Bukhalo 1988). As soon as a young mycelium began to appear on the surface of the agar medium, it was taken out with part of the medium, put into another Petri dish with a nutritious medium for the complete mycelium overgrowing (Maheshwari 2005). At the result, we received a strain of $C$. archeri that was used in our work under the number Sh01.

For the second stage, investigations of growth dynamics of $C$. archeri on different substrates and the process of overgrowing of the mycelium in laboratories were being held. Taking into account the trophic affiliation of $C$. archeri (Didukh 2009), the following combinations were used as a substrate:

1. soil (for the experiment, the upper layer of a forest soil of a sod-podzolic type that was free from the plant remnants was chosen),

2. beech sawdust (received as a result of picking healthy, newly-hewed wood, the size of the pieces was 1-2 mm),

3 . beech sawdust + soil (1:1),

4. beech shavings (received as a result of chipping healthy, newly-hewed wood, the size of the pieces ranged from $10 \times$ 10 to $40 \times 1 \mathrm{~mm}$ ).

Substrates were put into transparent heat-resistant polyethylene bags of 4 litres capacity. To each of these substrates, water was added in proportion $1 / 6$ of the final weight of the substrate. The bags with the substrates were being autoclaved
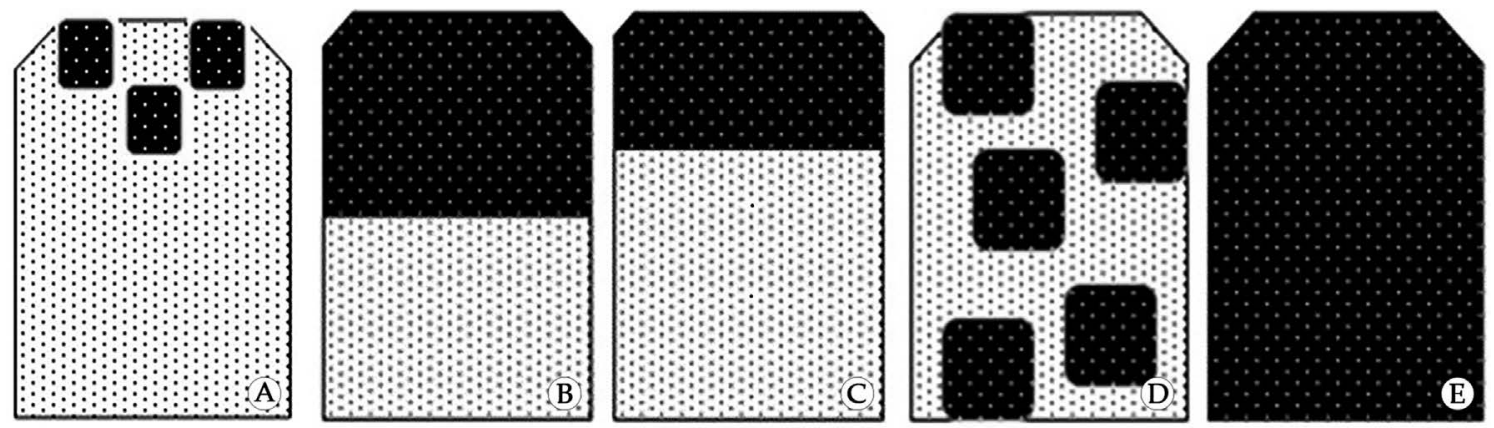

Figure 1. The diagram of stages of the substrate growth with mycelium of C. archeri: (A-C) growth of $1 / 4$ of the substrate; (B-D) growth of $1 / 2$ of the substrate; (E) 100\% growth of the substrate 
twice under the pressure of $1.5 \mathrm{~atm}$, for 1 hour each time. We inoculated the bags with the mycelium of $C$. archeri after cooling. The inoculated bags were placed into the incubator at a temperature of $22-24^{\circ} \mathrm{C}$ and monitored every day. The result was considered positive if the complete visual overgrowing of a substrate with a $C$. archeri mycelium could be observed that was infected by any extraneous microbiota The experiment was repeated 20 times.

In the course of the experiment, the following stages marked the growth of the substrate with mycelium (Fig.1).

The third stage - the concluding stage of the reproduction of this mushroom using the re-situ technology in nature. To actualize this stage, two monitoring reproductive sites, where C. archeri had never been grown before, were created. The main criteria for choosing the sites for applying the re-situ technology were the characteristics of natural places of growth of a mushroom, as well as the possibility to restrict the anthropogenic influence during the experiment.

C. archeri had been found in the territory of the park in beech plantations mixed with Silver Fir (Abies alba Mill.) with thin underbrush and slightly-decomposed forest litter of a mull type and in meadows. That is why, the mycological reserve 'Kamenystyi', where the conditions are identical to those in natural places of a mushroom growth in forest (reproductive monitoring site №1) and meadows of the National Nature Park Hutsulshchyna (reproductive monitoring site №2) was chosen for the realization of the reproductive technology. The reproductive monitoring site №1 (size $20 \times 60$ m) was located in a beech forest with Fagus sylvatica L. and admixture of Abies alba Mill., that were growing on acidic (pH of 3.7), brown forest light loamy soils. Forest litter was a mull type with a thickness of 7-10 cm. Age of plantations was approximately 110 years. Plant cover were Cardamine bulbifera L. Crantz, Oxalis acetosella L., Anemone nemorosa L., Galium odoratum L. and Viola odorata L. (Mosyakin, Fedoronchuk 1999).

The reproductive monitoring site №2 (size $20 \times 60 \mathrm{~m}$ ) was located on acidic ( $\mathrm{pH}$ of 3.3) underdeveloped turf soils with diluvia sediments. The thickness of the sod layer was $5-8 \mathrm{~cm}$. Plant cover were Carex umbrosa Hosd., Carex vulgaris Fries., Achillea millefolium L., Hypericum perforatum L., Leucanthe-

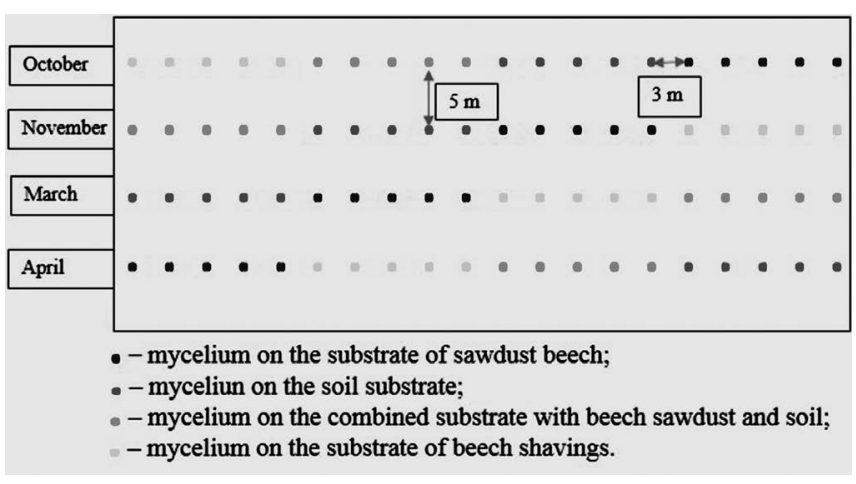

Figure 2. The scheme of introduction mycelia biomass in reproductive monitoring sites mum vulgare Lam. and Thymus serpyllum L. (Mosyakin and Fedoronchuk 1999).

Mycelium of $C$. archeri was inoculated into a soil of reproductive sites from October to November and in spring (March-April). Mycelium for inoculation have grown on different substrates. The substrate with mycelium was put in the upper layers of the soil in points, $400 \mathrm{~g}$ of substrate with mycelium, at a distance of 4-5 $\mathrm{m}$ apart in the reproductive monitoring sites. The mycelium was dug into turf in the meadows in places where there were no signs of haymaking and pastures. The location of the points was registered and marked with pegs and ribbons of different colours (Fig. 2).

All the substrates with the mycelium were put in the experimental sites. The monitoring of the reproductive sites was held simultaneously four times a month.

\section{Results and discussion}

During the first stage of the work, we succeeded in getting a pure culture of $C$. archeri. The colony of $C$. archeri in a culture had a white, unsolid, fluffy mycelium, which eventually gave a pink hue. In addition, the colony generated a large number of mycelium strands and aerial hyphae (Fig. 3). Reverse white, eventually became cream coloured. Clamp connections and anastomoses were present on hyphae. The speed of mycelium growth was $4-5 \mathrm{~mm} /$ day. These characteristics correspond to the features of this species, which have been described before (Bukhalo et al. 2009).

The research of growth of $C$. archeri on different substrate ( $2^{\text {nd }}$ stage) made it possible to identify the most favourable substrate for the reproduction of this rare mushroom among all those tested.

Dates of overgrowing of different substrates by the mycelium C. archeri is presented in the Table 1.

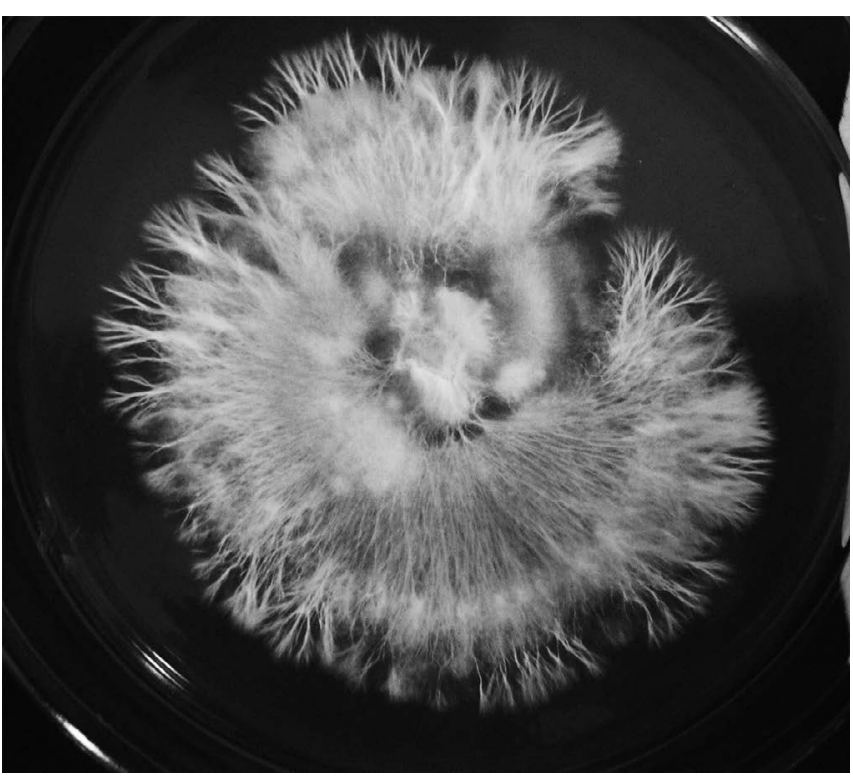

Figure 3 . The $C$. archeri colony on potato-glucose agar medium 
Table 1. Overgrowing of different substrates by the mycelium of Clathrus archeri

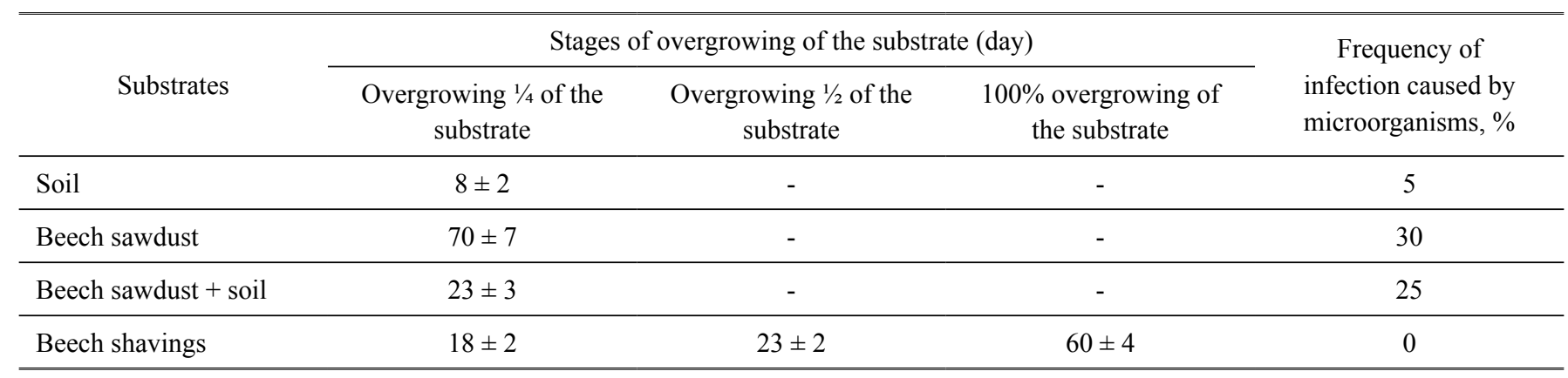

Notes: '- the overgrowing by the mycelium was not observed.

Based on the trophic affiliation of $C$. archeri to subsoil saprotrophs, we used the soil in a substrate to identity the natural conditions and promotion to the formation of the biomass of the mycelium (substrate N1). The mycelium that appeared on the soil on the 8th day of the experiment was white (Fig. 4). The diameter of the mycelia strands ranged from 0.5 to $1.5 \mathrm{~mm}$. The branching was dense and 'tree-like'. The main (thicker ones) and newly-created (thinner ones) strands were clearly seen. Also, the formation of a large number of branched aerial hyphae was observed. The mycelium couldn't penetrate into the substrate and grew only on the surface. The process of its overgrowing into the depth of the bag was impossible through a rather high density of a soil substrate. Despite the fact that the mycelium began to overgrow the substrate of the soil very fast, the percentage of the area covered with it was not changed.

On the substrate of sawdust beech (substrate N 2), the $C$. archeri colony was formed only on the $70^{\text {th }}$ day after inocu-

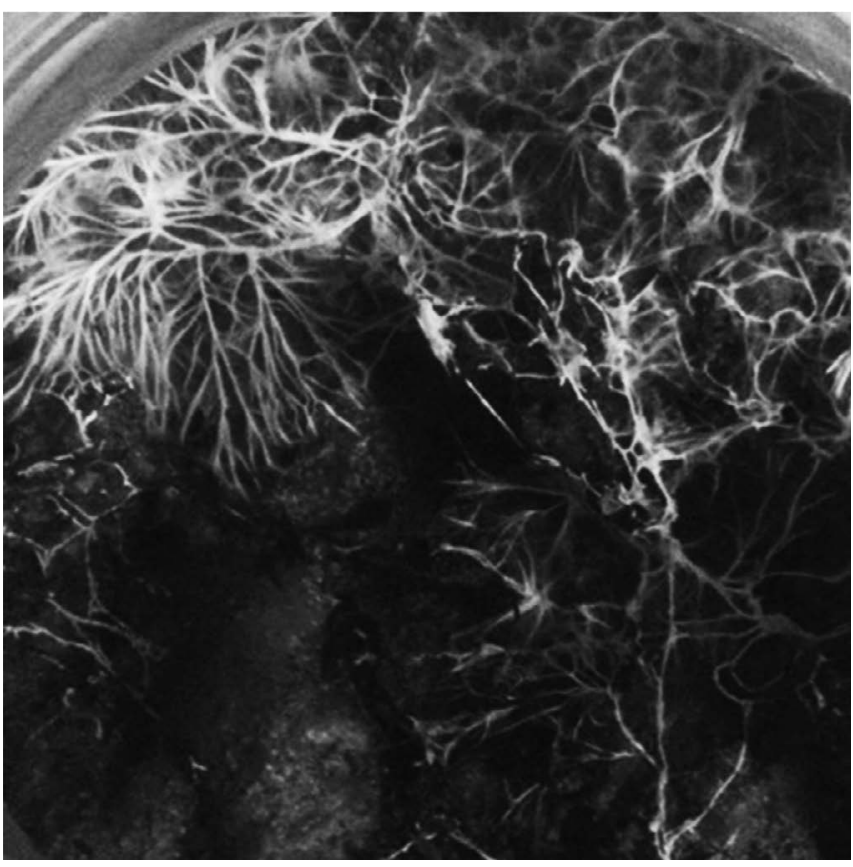

Figure 4. The mycelium overgrowing of the soil substrate (8 days after inoculation) lation. The mycelium did not form branching on the apical surface of the substrate and all biomass of mycelium was accumulated near the place of inoculation. Mycelium did not spread into the deep of the substrate.

Typically, the usage of a well-stirred mixture of sawdust and soil (substrate N 3) for the optimization of characteristics of the mycelium growth gave a better result only in comparison with sawdust (substrate N 2). Colony of $C$. archeri was formed on the apical part of the substrate on the $23^{\text {rd }}$ day after inoculation (Fig. 5 A). On the $88^{\text {th }}$ day of cultivation, the mycelium penetrated into the substrate and formed a white netted of branching measuring 4-20 mm (Fig. 5 B).

Beech shavings (substrate N 4) turned out to be the optimal substrate for the growth of mycelium of $C$. archeri. The mycelium completely penetrated the apical area of the substrate on the $18^{\text {th }}$ day. On the $23^{\text {rd }}$ day, the fungus reached half of the visible area of the experimental sample (Fig. $6 \mathrm{~A}$ ); and on the $60^{\text {th }}$ day, almost $100 \%$ overgrowth of the substrate with the mycelium could be seen (Fig. 6 B). Colony of C. archeri formed white mycelia strands $0.5-1 \mathrm{~mm}$ of thickness and had spider web like branching across $2-5 \mathrm{~mm}$ (Fig. $6 \mathrm{C}$ ).

We consider that in this case, the positive effect on the mycelium growth had been caused by the improved aeration of the substrate. It related with lower density of substrate in the process of its formation in comparison to sawdust and soil. Beech shavings were least influenced by the infection caused by an alien species of myco- and microbiota.

The main differences of the mycelium grown on different substrates related to the completeness of the overgrowth of the substrate by the mycelium, the frequency of the fungus branching, and the 'pattern', created by the branching.

Basidiomata of $C$. archeri was formed only on the reproductive sites where mycelium grew on the substrate with beech shavings. The terms of the appearance of the first basidioma of the $C$. archeri are given in Table 2.

The first basidioma of $C$. archeri appeared 570 days after mycelium introduction in the monitoring reproductive site № 2 . On other sites, fruit bodies formed latter. Young basidioma had the form of an egg with size of 2-7 cm, which formed four pink arms after 4-7 days. The inner surface of the arms was covered in olive green gleba (Fig. 7 A-C). 

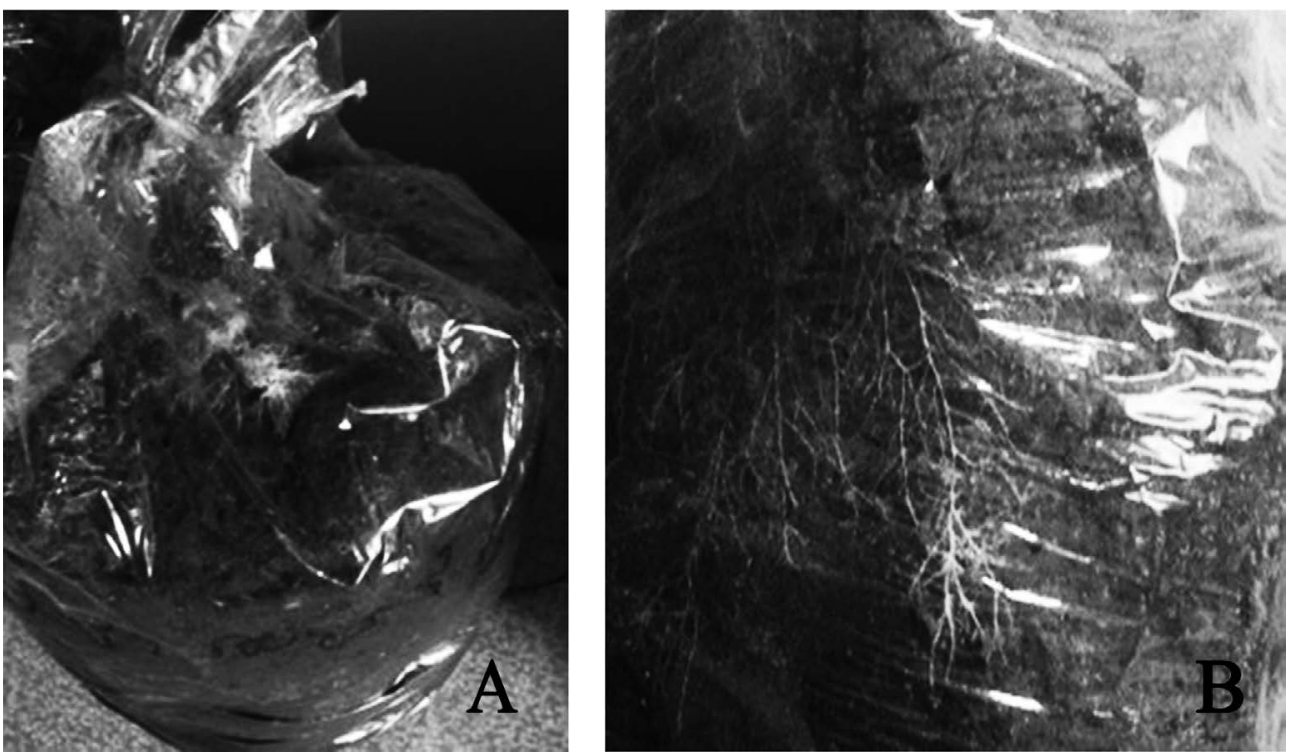

Figure 5. The mycelium growing on the mixture of sawdust and soil: A -23 days after inoculation; B -88 days after inoculation
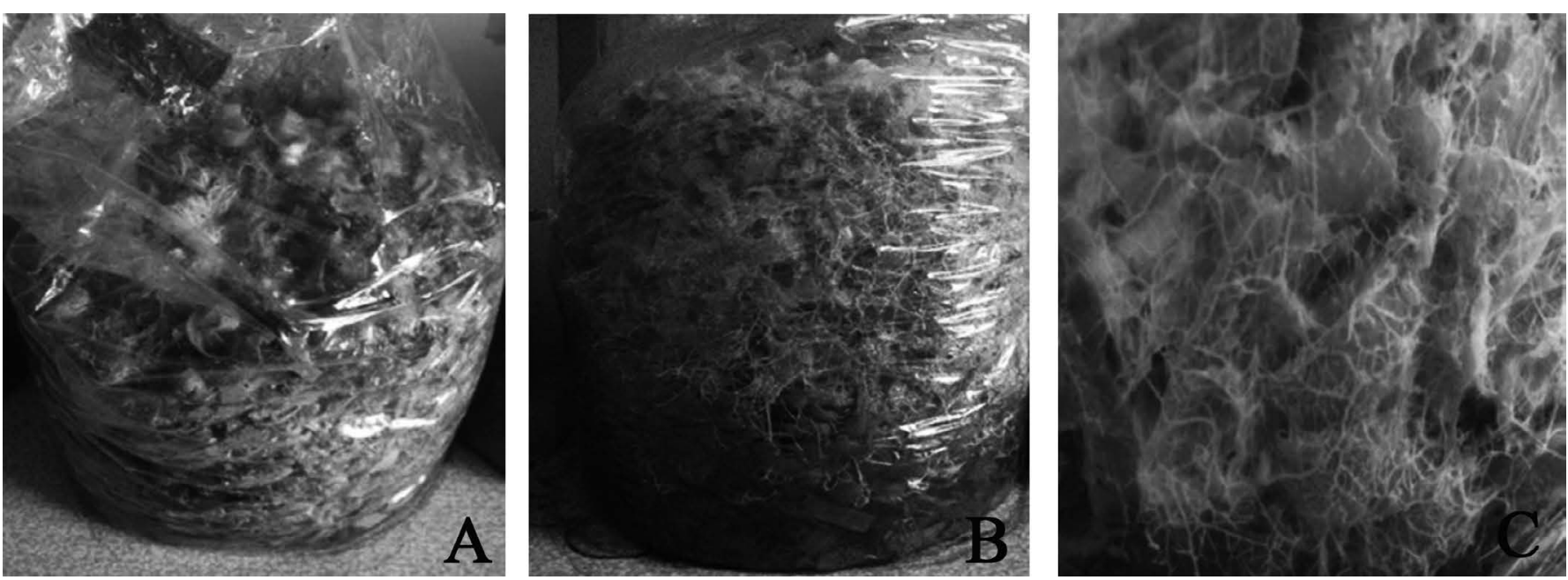

Figure 6. The mycelium growing on the substrate of beech scobs: A-23 days after inoculation; B - 60 days after inoculation; $\mathrm{C}-$ white mycelia strands

Table 2. The basidioma formation of Clathrus archeri after putting the mycelium growth on the substrate with beech shavings (re-situ reproduction)

\begin{tabular}{|c|c|c|c|c|}
\hline \multirow{2}{*}{$\begin{array}{c}\text { Monitoring reproductive } \\
\text { site }\end{array}$} & \multirow{2}{*}{$\begin{array}{l}\text { Date of putting } \\
\text { of mycelium }\end{array}$} & \multicolumn{3}{|c|}{ Basidioma formation of $C$. archeri } \\
\hline & & $\begin{array}{l}\text { Successful of basidioma } \\
\text { formation }(+)\end{array}$ & $\begin{array}{c}\text { Date of emergence of } \\
\text { basidioma }\end{array}$ & $\begin{array}{l}\text { Number of days before } \\
\text { occurrence of basidioma }\end{array}$ \\
\hline \multirow{2}{*}{$\begin{array}{c}\text { №1 } \\
\text { (Beech forest) }\end{array}$} & 6.11 .2012 & + & 25.09 .2014 & 709 \\
\hline & 11.03 .2013 & - & - & - \\
\hline \multirow{4}{*}{ №2 (Meadows) } & 10.10 .2012 & + & 10.09 .2014 & 730 \\
\hline & 6.11 .2012 & + & 25.10 .2014 & 749 \\
\hline & 1.03 .2013 & + & 10.09.2014 & 570 \\
\hline & 3.04 .2013 & + & 25.10 .2014 & 592 \\
\hline
\end{tabular}

Notes: '-' basidioma no formed. 

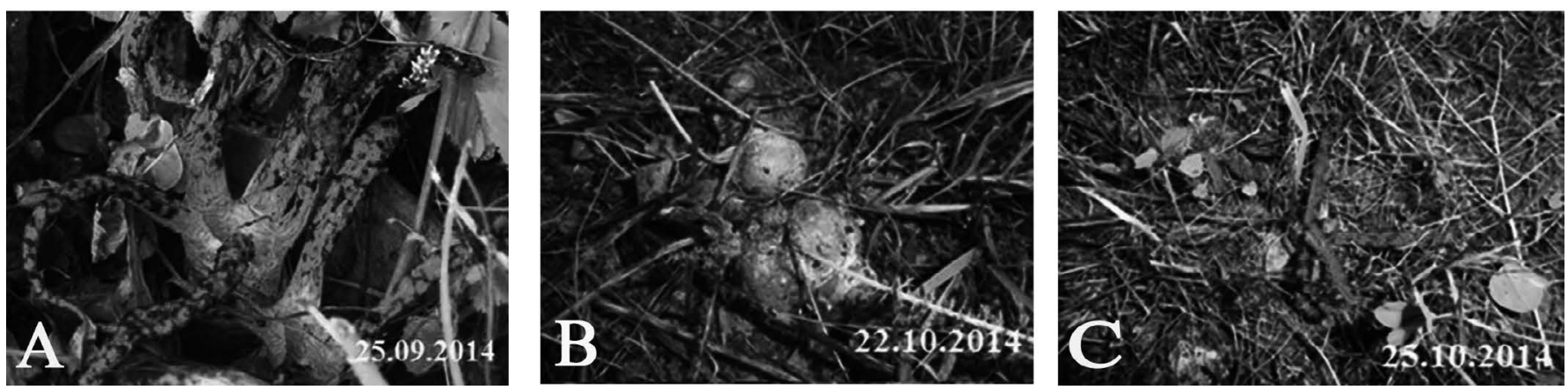

Figure 7. The basidioma of $C$. archeri received by the re-situ method: A - in Monitoring reproductive site №1 (Beech forest); B - the young fruiting bodies ('egg' stage) in Monitoring reproductive site №2 (Meadow); C - the basidioma of C. archeri with red arms that grew in meadow

We suppose that the possibility of a positive result (getting basidioma) increases proportionally to the ability of a mycelium to overgrow a substrate, creating the biggest biomass. Such a substrate in our experiment turned out to be beech's shavings.

Concerning the differences in terms of $C$. archeri fruiting on the experimental sites, it should be noted that the conditions on meadows appeared to be most suitable for the realization of reproductive technologies. The term of getting the fruit bodies decreased from 23 months in forests to 19 on meadows.

It may be caused by the ability of herbaceous plants to form complete vegetation on meadows. Their roots are closely intertwined, forming sod that securely protects soil from drying and destruction. In forests, fallen leaves and needles from beech don't provide the needed splendour of litter. The penetration of air, warmth, and moisture in forests with the litter of a mull type is complicated, slowing its decomposition that evidently affects the formation of basidioma. In addition, the presence of fallen beech leaves in an underlay causes the acidification of soil that is the reason for slower soil formation and rotting of underlay, in comparison to deciduous forests and meadow, where beeches don't grow. It was also established that putting the mycelium of mushrooms into the turf on meadows in spring months reduced the term of beginning of fruiting. Planting the mycelium in spring in forest site have not given any results in the formation of fruit bodies of mushrooms but they are forming in places where mycelium was planted in autumn. That is why, it is better to implement the inoculation of mycelium of $C$. archeri in the conditions of beech forest in autumn.

\section{Conclusions}

Thus, the results of our experiments made it possible to perform the technology of regeneration of mushrooms included in the Red Data Book of nature, for example, of C. archeri, successfully. For this purpose, we suggested using the re-situ technology (Petrichuk et al. 2014). It was found that the substrate on which the mycelium was grown and subsequently used for natural conditions had a significant influence on the success of 'reinoculation' of $C$. archeri. Among all the investigated substrates, only one (beech shavings) proved to be suitable for the growth of sowing mycelium of $C$. archeri.
The research shows that the reproduction of $C$. archeri in nature should be held on non-forest experimental sites, mainly on meadows during the spring months. The positive result (the fruiting of a fungus) may be gained by putting the mycelium of $C$. archeri into the forest soil in autumn. Monitoring of the laid experimental areas will be conducted in the future, and it will become the basis for investigation of the fruiting frequency of $C$. archeri in those sites.

\section{Conflict of interest}

The Authors declare no conflict of interest.

\section{Acknowledgment and source of funding}

The research was funded from personal means.

\section{References}

Allen J.L., Lendemer J.C. 2015. Fungal conservation in the USA. Endangered species research 28: 33-42. DOI 10.3354/esr 00678.

Birsan C., Cojocariu A., Cenusa E. 2014. Distribution and Ecology of Clathrus archeri in Romania. Notulae Scientia Biologicae 6(3): 288-291. DOI 10.15835/nsb.6.3.9389.

Bukhalo A.S. 1988. Higher Edible Basidiomycetes in Pure Culture. Naukova Dumka, Kiev. ISBN 5-12-000267-6.

Bukhalo A., Myckchaylova O., Lomberg M., Wasser S. 2009. Microstructures of vegetative mycelium of macromycetes in pure culture. M.G. Kholodny Institute of Botany, National Academy of Sciences of the Ukraine; Faculty of Science \& Science Education and Institute of Evolution, University of Haifa, Israel., 104 p. ISBN 978-966-642-408-6.

Didukh Y.P. 2009. The Red Data Book of Ukraine Flora. Global consulting, Kyiv. ISBN 978-966-97059-0-7.

Hawksworth D.L. 1991. The fungal dimension of biodiversity: magnitude, significance and conservation. Mycological Research 95(6): 641-655. DOI 10.1016/S0953-7562(09)80810-1.

Maheshwari R. 2005. Fungi: Experimental Methods in Biology. CRC Press Taylor and Francis Group, Florida, USA, 264 p. ISBN 978-1-57444-468-1.

Malaniuk V.B. 2013. New records of macromycetes from the Red Data Book of Ukraine in Halych National Nature Park. Ukrainian Botanic Journal 70(2): 251-255. 
Mosyakin S.L., Fedoronchuk M.M. 1999. Vascular plants of Ukraine. A nomenclatural checklist. National Academy of Sciences of the Ukraine M.G. Kholodny Institute of Botany, Kiev. ISBN 966-02-1336-0.

Petrichuk Y.V., Pasaylyuk M.V., Sukhomlyn M.M. 2014. Preservation of Rare Fungi Species. Materials of the $3^{\text {rd }}$ International Scientific Conference Technology re -situ "Flora in the Red Book of Ukraine: introduction of the Global Strategy of Plants Protection". Lviv, 6-7 June 2014, 232-234.

Petrichuk Y.V., Pasaylyuk M.V. 2015. New records of the fungi listed in the Red Data Book of Ukraine from the Pokutski Carpathians. Ukrainian Botanic Journal 72(4): 381-384. DOI 10.15407/ ukrbotj72.04.381.

Szczepkowski A., Obidziński A. 2012. Alien species of stinkhorns Phallaceae in forests of Poland. Studia i Materiaty Centrum Edukacji Przyrodniczo-Leśnej Rogów 33(4): 279-295.
Venturella G. 2004. Mycological investigations and conservation of fungi in Sicily (South Italy). Mycologia Balcanica 1: $21-23$.

Zykova M.O. 2007. New records of Anthurus archeri (Berk.) E. Fisch. (Clathraceae, Basidiomycota) in Ukraine. Chornomorski Botanical Journal 3(2): 124-128. DOI 10.14255/2308-9628/07.32/13.

\section{Authors' contribution}

M.P. - study concept, assumptions, goals and research, field work, data analysis; Y.P. - study concept, assumptions, goals and research, field work, data analysis, review of bibliography; N.T. - review of bibliography, preparation and text editing; M.S. - review of bibliography, preparation and text editing.

Zatwierdzam do druku po wprowadzeniu zaznaczonych poprawek. Praca została przejrzana i zaakceptowana do druku przez wszystkich współautorów. Jednocześnie załączam oświadczenie o oryginalności pracy, etyczności i konflikcie interesów oraz umowę licencyjną Creative Commons (BY-NC-ND 3.0). 